EPiC Series in Engineering
Volume 3, 2018, Pages 715-724
HIC 2018. 13th International
Conference on Hydroinformatics

\title{
Comparison between calibration and sensitivity approaches in water network management in emergency conditions
}

\author{
Fiorini Morosini A. ${ }^{1}$, Caruso O. ${ }^{1}$, Veltri P. ${ }^{1}$ \\ Università della Calabria - Dipartimento di Ingegneria Civile, Rende (CS) 87036, Italy \\ attilio.fiorinimorosini@unical.it
}

\begin{abstract}
When a network works in emergency conditions, due to a pipe failure, an appropriate management of the system is necessary. These events can cause a bad service for the users, because the pressure in some nodes of the network (critical nodes) decreases and the required demand is not guaranteed. In fact, a pipe failure causes the isolation of the intervention area, modifies the circulating flow along pipes and can produce a pressure reduction in some nodes.

In network management the aim is to increase the pressure, and consequently the flow rate delivered at critical nodes in order to minimize disruptions during the time between the failure and the repair.

In this paper, a methodology based on the nodal demand control is proposed. The nodal demand control proposed is possible by using control valves and by identifying the nodes where the control should be done. The control nodes can be chosen by using sensitivity matrices or an approach based on calibration techniques. A case study shows the results obtained with both methods for the real network of Praia a Mare in the South of Italy.

Keywords: Calibration, Nodal Demand Control, PDA Analysis, Pipe Burst, Sensitivity Matrices, Water Distribution Systems (WDS), Water Network Analysis.
\end{abstract}




\section{Introduction}

During emergency conditions, such as failures of one or more components of the system or ordinary maintenance of its components, management programs to limit the problems for the users should be implemented. In fact, through the control of hydraulic parameters, a correct management of WDS is possible to improve the systems efficiency minimizing failures and guarantying adequate levels of service for the users.

The issues connected with the WDS management in emergency conditions was being widely studied by the scientific community and some Authors proposed different methodologies to prevent failures in pipe networks and to ensure the long-term system efficiency.

Optimization and decision support techniques are related to economic parameters and based both on the minimization of the repair and maintenance costs (Lansey, Duan, Mays, \& Tung, 1992), (Kleiner, Adams, \& Rogers, 1998) and on the definition of performance and economical indexes (Gargano \& Pianese, 200), (Berardi, Colombo, \& Giustolisi, 2008), (Farmani, Walters, \& Savic, 2005). Further models considered a multi-objective algorithm to obtain the optimal sequence of repair works, based on maximization of reliability and minimization of the costs(Alvisi \& Franchini, 2006).

These approaches analyse the network by preventing the pipe failure, but it is also necessary to operate after the failure has happened.

In this paper, a new approach to manage network based on a PDA model with a defined subset of valves is proposed. The aim is to improve the head in the critical areas of the network and to increase the effective delivered flow in critical nodes using a new nodal demand distribution at nodes.

\section{Method}

When in a network a failure occurs, the area where the burst pipe is located must be isolated by closing a subset of shut-off valves. It allows to repair pipe but, at the same time, it is necessary to guarantee a good level of service in other areas of the network. These operations cause a variation of the flow rate along pipes and the pressure at each nodes changes. In some nodes, the pressure can decrease and, consequently, the effective delivered flow can be less than the required one.

A methodology to increase the pressure and the effective delivered flow in important nodes of the network, here defined as critical nodes (i.e., hospitals, vulnerable customers, etc), is proposed. In this case the flow rate at each node can be modified by using pressure reduce valves (PRV) to ensure users get a defined flow rate limited by imposed pressure. The network analysis must be carried out using a PDA model, as INetPDA (Veltri, Fiorini Morosini, \& Orlando, 2010), that allows to calculate the effective demand delivered at each node when the head is lower than a defined value $\mathrm{H}_{\text {max }}$.

The head $\mathrm{H}_{\text {max }}$ to guarantee at each node is related to the ground level, $\mathrm{z}$, and to the height of each supplied building, $\mathrm{H}_{\mathrm{b}}$; it can be defined by the relationship:

$H_{\max }=z+H_{b}+P_{m s}+P_{p}+P_{D}$

where:

- $\quad \mathrm{P}_{\mathrm{ms}}$ is the minimum pressure necessary to serve each user;

- $\quad \mathrm{P}_{\mathrm{p}}$ are the head losses along the riser column;

- $\quad P_{D}$ are the head losses starting from the network node and ending at the base of each building. 
When the head is lower than $\mathrm{H}_{\max }$ the system works in PDA conditions (Calomino \& Veltri, 1980)and the delivered demand Qrealis lower than requested demand Qreq, depending on the real head value as shown in figure 1.

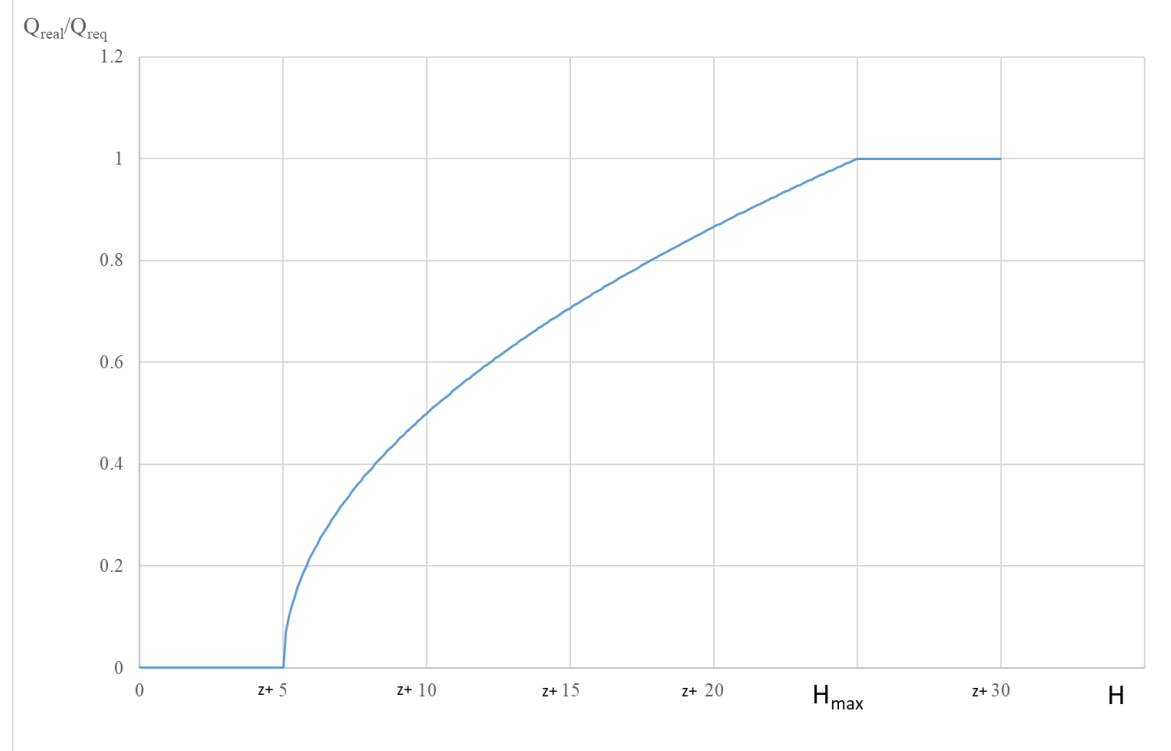

Figure 1: Ratio between Qreal and Qreq versus real head $\mathrm{H}$ at node

It is necessary to define in which node it is convenient to modify the base demand by installing PRV valves (figure 2) for the demand control. The nodal output demand control could be done through valves which fix the head Hred at the system nodes by forcing the given flow rate Qred downstream of the node. 


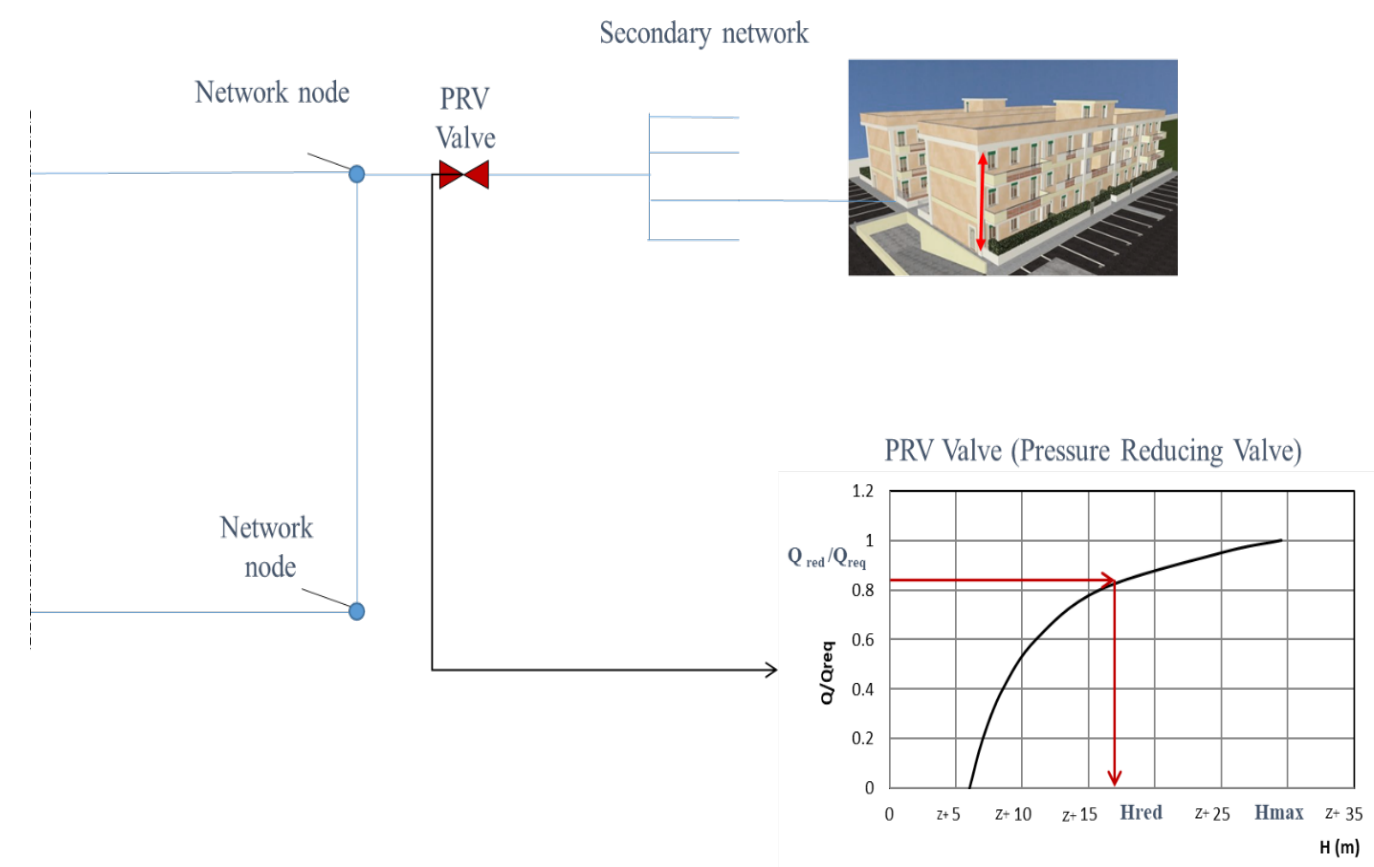

Figure 2: Demand control at a node adopting PRV Valve

In this paper, two different methodologies have been proposed: the first is based on calibration procedure, the second one is a different approach based on sensitivity matrices.

\subsection{Calibration procedure}

In the first case, the nodal demand distribution has been defined by using an approach based on a calibration procedure and fixing the minimum required heads at critical nodes.

When a pipe failure occurs and the area where the pipe is located is isolated, the network topology changes and the new conditions can determine the inefficiency of the system because the head at some nodes (here named critical nodes) decreases.

To increase head in critical nodes the idea is to reduce the requested demand in some others nodes, so the total amount of circulating flow in the network decreases.

To define the new set of requested demand at each node, a new methodology based on calibration approach has been proposed. WDS calibration methods are commonly used to obtain the values of roughness in pipes and real flow rate at nodes, which are considered input parameters in network analysis, by comparing pressure at nodes and flow along pipes obtained by the model with field data.

The head $\mathrm{H}_{\max }$ at critical nodes can be hypothesized as the measured one in the modified network, in which the area with burst pipe is isolated.

Fixing this head as a field data in a calibration procedure, the goal becomes to define the input parameters for the network model and the base demand at each node.

The calibration model used is UNINET (Veltri, Fiorini Morosini, \& Orlando, 2010), based on a Bayesian-statistical approach, that uses a SCEM-UA algorithm version (Vrugt, Gupta, Bouten, \& Sorooshian, 2003) for the analysis of water networks (Kapelan, Savic, \& Walters, 2007)with a simulation model (INetPDA) in PDA condition.

The UNINET algorithm is showed in figure 3. 
By this approach, Hmax is the input head in calibration model applied to the network and the effective topology is that obtained by isolating the area where the pipe failure is located.

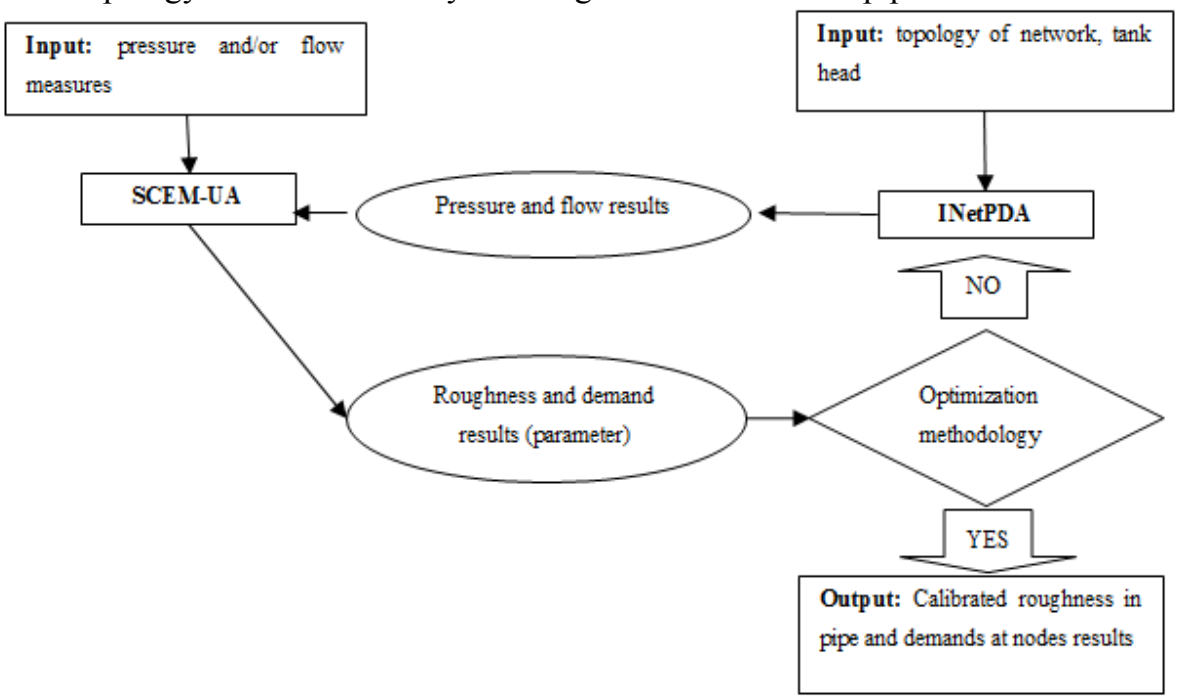

Figure 3:UNINET Algorithm

\subsection{Sensitivity matrices}

In the second approach the new demand distribution in the so called sensitive nodes of the network is fixed. These nodes are defined by using the sensitive matrices, in which each element represents the pressure variation when a variation of the demand at nodes or of the roughness coefficient in pipe occurs. The model employs the Max-Sum Method (Bush \& Uber, 1998).

In particular, each element of the matrix $\mathrm{S}_{\mathrm{p}, \mathrm{Q}}$ (Equation 2) represents the variation in pressure versus the variation of the demand at nodes, $Q_{j}$, of the $j$-th pipe and $S_{p, \varepsilon}$ (Equation 3) represents the variation in pressure versus the variation of the roughness coefficient, $\varepsilon_{j}$, of the $j$-th pipe.

$\mathrm{S}_{\mathrm{p}, \mathrm{Q}}=\left[\begin{array}{ccc}\partial \mathrm{p}_{1} / \partial \mathrm{Q}_{1} & \ldots & \partial \mathrm{p}_{1} / \partial \mathrm{Q}_{\mathrm{n}} \\ \vdots & \ddots & \vdots \\ \partial \mathrm{p}_{\mathrm{n}} / \partial \mathrm{Q}_{1} & \ldots & \partial \mathrm{p}_{\mathrm{n}} / \partial \mathrm{Q}_{\mathrm{n}}\end{array}\right]$
$S_{p, \varepsilon}=\left[\begin{array}{ccc}\partial p_{1} / \partial \varepsilon_{1} & \ldots & \partial p_{1} / \partial \varepsilon_{l} \\ \vdots & \ddots & \vdots \\ \partial p_{n} / \partial \varepsilon_{1} & \ldots & \partial p_{n} / \partial \varepsilon_{l}\end{array}\right]$

For each possible failure, the analysis defines a different nodal demand distribution because the critical nodes and the related head values vary. 


\section{Results and discussion}

Both the methodologies were applied to a real case, the network of Praia a Mare (Italy), a city in the South of Italy. The network consists of 73 pipes, 53 nodes and 2 source/tanks with a fixed head (Caruso, 2017).

The total base demand is $47.25 \mathrm{l} / \mathrm{s}$. The head $\mathrm{H}_{\max }$ varies from $29 \mathrm{~m}$ to $68 \mathrm{~m}$. The number and the position of shut-off valves are known, as shown in figure 4.

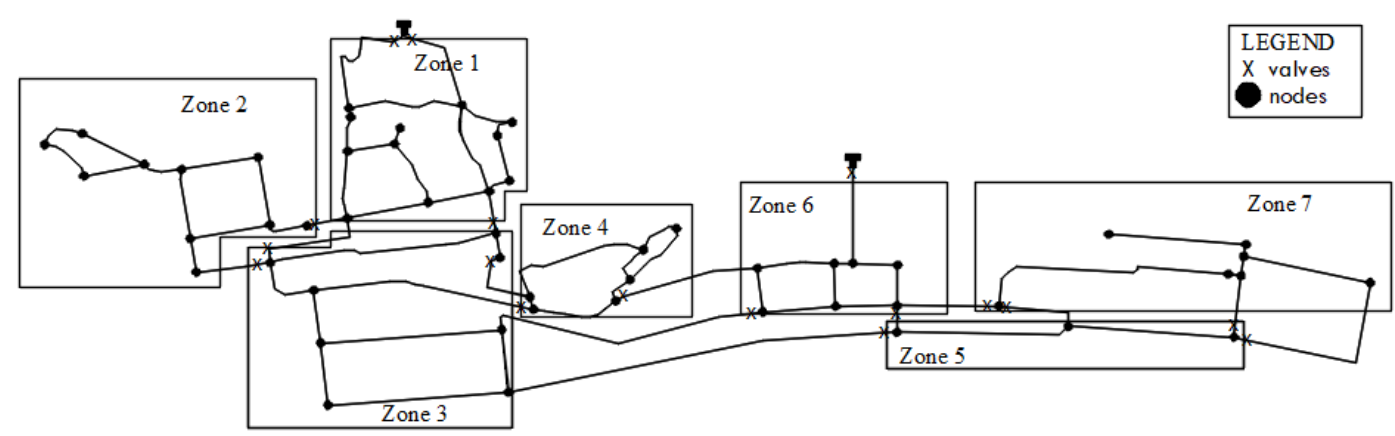

Figure 4:Shut-off Valves in the Network

By considering, for example, a failure of a pipe located in the zone 1, it is necessary to isolate the area in order to allow the pipe repair work. In this case, the flow rate of the isolated zone is $8.861 / \mathrm{s}$, so the required total demand in DDA conditions is $\mathrm{Q}_{\mathrm{req}}=38.36 \mathrm{l} / \mathrm{s}$.

In this new configuration (figure 5), the effective circulating flow in the network in PDA conditions is $35.56 \mathrm{l} / \mathrm{s}$ because there are 19 critical nodes that deliver a total flow rate of $14.45 \mathrm{l} / \mathrm{s}$, instead of 17.25 $1 / \mathrm{s}$ with an undelivered demand at critical nodes $\mathrm{Q}_{\text {fail }}=2.8 \mathrm{l} / \mathrm{s}$.

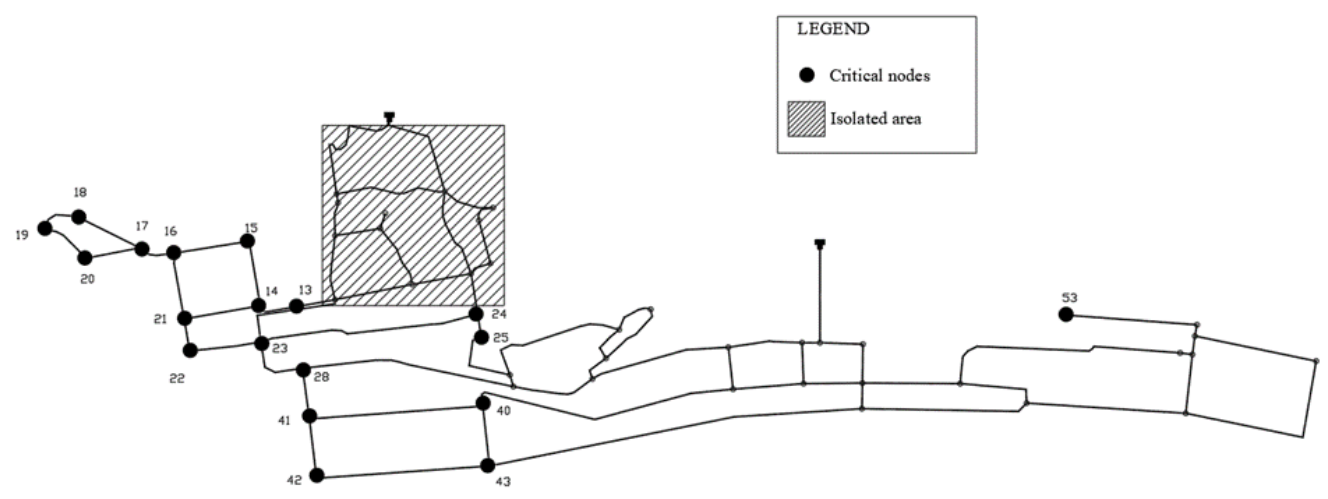

Figure 5: Critical Nodes

With a new distribution of nodal demand,defined using calibration procedure or sensitive matrices, the heads and the effective delivered flows at critical nodes change. 


\subsection{Results adopting calibration approach}

For the proposal scenario with the 19 critical nodes, once fixed the head values $\mathrm{H}_{\max }=\mathrm{z}+25 \mathrm{~m}$ at the critical nodes, the calibrated nodal demand values, $Q_{c a l}$, have been obtained by calibration model. The new total demand distribution, Qred, is defined as the sum of the requested demand Qreqi at the critical nodes and the minimum value between the calibrated nodal demand values, $Q_{\text {cali, and the }}$ requested demand $Q_{\text {reqi }}$ at the other ones.

Assuming Qredi as the new base demand at each node, the analysis in PDA can be carried on. In these conditions the calculated heads at critical nodes, Herog, and the effective delivered flows, Qerog, increase. The total circulating flow $Q_{\text {red }}$ in the network is reduced to $35.78 \mathrm{l} / \mathrm{s}$ instead of $38.36 \mathrm{l} / \mathrm{s}$ corresponding to the failure scenario.

Flow rate values obtained for critical nodes are shown in table 1.

\begin{tabular}{lrrrrrr}
\hline $\begin{array}{l}\text { Node } \\
\mathrm{s}\end{array}$ & $\begin{array}{r}\text { Qreq } \\
(1 / \mathrm{s})\end{array}$ & Qfail $(1 / \mathrm{s})$ & Qcal $(1 / \mathrm{s})$ & Qred $(1 / \mathrm{s})$ & Qerog $(1 / \mathrm{s})$ & (Qerog-Qfail)/Qfail \\
\hline 13 & 0.320 & 0.222 & 0.613 & 0.320 & 0.223 & $0.67 \%$ \\
14 & 0.760 & 0.508 & 1.645 & 0.760 & 0.512 & $0.72 \%$ \\
15 & 0.610 & 0.407 & 1.134 & 0.610 & 0.410 & $0.72 \%$ \\
16 & 0.740 & 0.494 & 1.134 & 0.740 & 0.498 & $0.72 \%$ \\
17 & 0.680 & 0.417 & 1.134 & 0.680 & 0.421 & $1.02 \%$ \\
18 & 0.490 & 0.474 & 1.134 & 0.490 & 0.476 & $0.41 \%$ \\
19 & 0.450 & 0.364 & 1.134 & 0.450 & 0.366 & $0.59 \%$ \\
20 & 0.490 & 0.442 & 1.134 & 0.490 & 0.444 & $0.47 \%$ \\
21 & 0.760 & 0.566 & 1.134 & 0.760 & 0.570 & $0.85 \%$ \\
22 & 0.450 & 0.340 & 1.134 & 0.450 & 0.343 & $0.86 \%$ \\
23 & 1.930 & 1.555 & 1.134 & 1.930 & 1.568 & $0.85 \%$ \\
24 & 1.140 & 0.997 & 1.134 & 1.140 & 1.005 & $0.84 \%$ \\
25 & 0.400 & 0.350 & 1.134 & 0.400 & 0.353 & $0.84 \%$ \\
28 & 1.270 & 1.094 & 1.134 & 1.270 & 1.106 & $1.08 \%$ \\
40 & 1.910 & 1.685 & 1.134 & 1.910 & 1.705 & $1.20 \%$ \\
41 & 1.100 & 1.008 & 1.134 & 1.100 & 1.018 & $0.99 \%$ \\
42 & 0.910 & 0.866 & 1.134 & 0.910 & 0.874 & $0.92 \%$ \\
43 & 2.290 & 2.186 & 1.134 & 2.290 & 2.209 & $1.05 \%$ \\
53 & 0.550 & 0.550 & 1.134 & 0.550 & 0.550 & $2.00 \%$ \\
\hline
\end{tabular}

Table 1: Flow rate values obtained for critical nodes

The increments of head and flow rate in each node are shown in figure 6. 


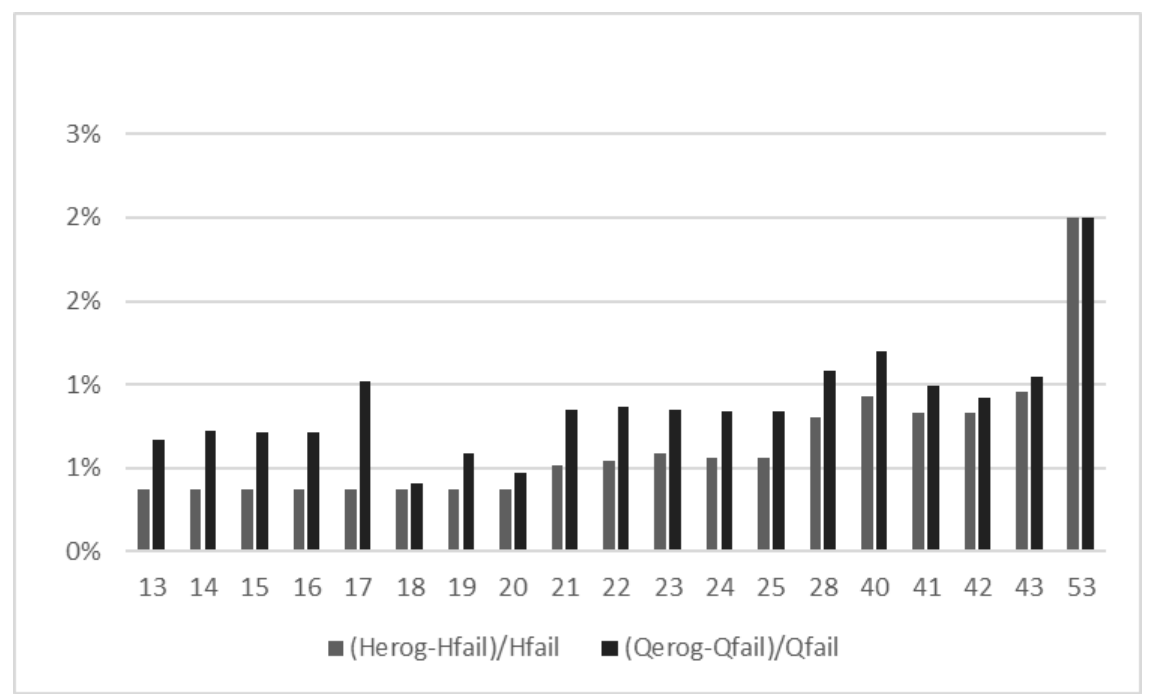

Figure 6:Increment of flow rate and head at each node in failure condition and after redistribution of demand

The improvement is negligible, but it could be useful once assumed that for a correct WDS management it is necessary to guarantee an adequate delivered flow especially at nodes (i.e. hospitals, vulnerable customers) in which a disruption, even if temporary, is not acceptable. Taking into account this management aspect, the obtained results are interesting. This procedure allows to increase the head values in the critical area, by managing the demand at the other nodes by fixing an adequate head and reducing the circulating flow in the network.

\subsection{Results adopting sensitivity matrices methodology}

By adopting the sensitivity matrices methodology, some better results in terms of increment of flow rate are obtained.

The first 18 sensitive nodes obtained using sensitivity matrices for the assumed scenario are indicated in figure 7 and in table 2.

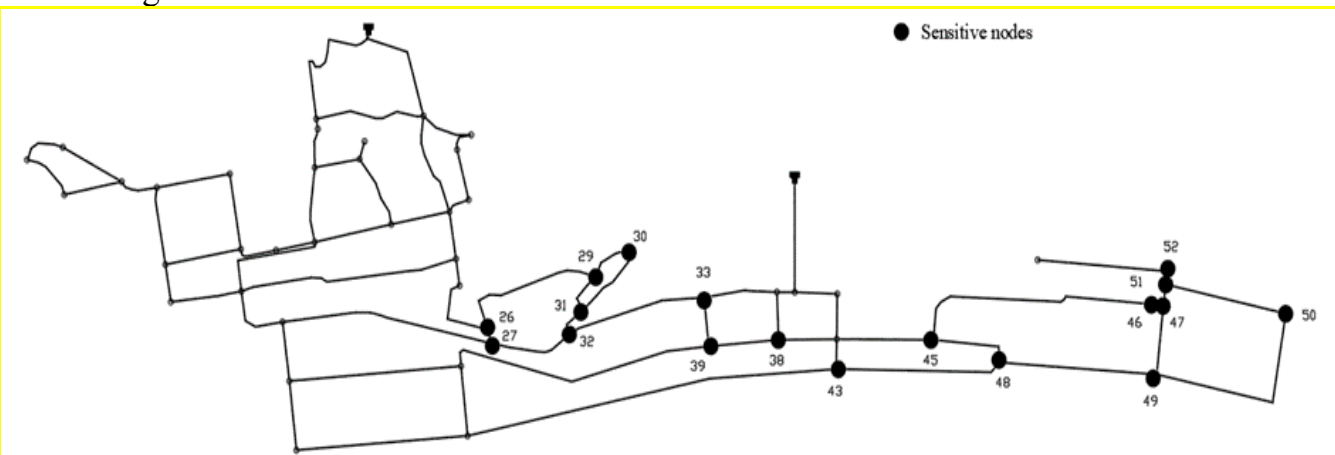

Figure 7: Sensitive Nodes Figure 7 


\begin{tabular}{|c|c|c|c|c|c|c|c|c|c|c|c|c|c|c|c|c|c|c|}
\hline $\begin{array}{l}\text { Positio } \\
\mathrm{n} \text { in } \\
\text { matrice } \\
\mathrm{s}\end{array}$ & 1 & 2 & 3 & 4 & 5 & 6 & 7 & 8 & 9 & 10 & 11 & 12 & 13 & 14 & 15 & 16 & 17 & 18 \\
\hline $\begin{array}{l}\text { Sensiti } \\
\text { ve } \\
\text { nodes }\end{array}$ & 46 & 49 & 50 & 51 & 52 & 47 & 48 & 45 & 26 & 27 & 44 & 29 & 30 & 31 & 39 & 38 & 32 & 33 \\
\hline
\end{tabular}

Table 2: Sensitive Nodes hierarchy

These results have been obtained by varying the number of sensitive nodes where the pressure control should be assumed.

The parameter $\Psi$ is the flow rate increment at critical nodes obtained reducing flow rate at sensitive nodes of the network by using PRV valves. The results are shown in table 3.

\begin{tabular}{lrrrr}
\hline $\begin{array}{l}\text { Number of } \\
\text { sensitive } \\
\text { nodes }\end{array}$ & $\begin{array}{r}\psi \text { for a } \\
\text { variation } \\
\text { of 5\% }\end{array}$ & $\begin{array}{r}\psi \text { for a variation } \\
\text { of 10\% }\end{array}$ & $\begin{array}{r}\psi \text { for a variation } \\
\text { of } 15 \%\end{array}$ & $\psi$ for a variation of $20 \%$ \\
\hline 2 & $0.62 \%$ & - & - & - \\
3 & $0.62 \%$ & - & - & - \\
4 & $0.62 \%$ & $1.18 \%$ & - & - \\
7 & $0.62 \%$ & $1.18 \%$ & $1.59 \%$ & $2.91 \%$ \\
9 & $0.83 \%$ & $1.52 \%$ & $2.21 \%$ & $3.53 \%$ \\
12 & $0.97 \%$ & $1.87 \%$ & $2.70 \%$ & $3.46 \%$ \\
15 & $0.97 \%$ & $1.80 \%$ & $2.63 \%$ & $3.11 \%$ \\
18 & $0.90 \%$ & $1.59 \%$ & $2.42 \%$ & \\
\hline
\end{tabular}

Table 3: Flow rate increment obtained in critical nodes using sensitive matrices procedure

The flow rate deficit recovered with the management increases with the reduction of flow at the sensitive nodes, because the head loss decreases and consequently the pressure in the nodes increases, due to theless flow circulating in the networks.

In this case study, the procedure using sensitivity matrices is better than calibration approach.

This result is important in management for critical nodes in which a disruption, even if temporary, is not acceptable, and it is possible to limit diseases in these node limiting flow rate in the network for the time strictly necessary to repair the pipe.

\section{Conclusions}

In this paper, a methodology for emergency management of WDS has been proposed. The methodologyis based on a redistribution of flow rate at each node with nodal demand control using pressure reduce valves (PRV). The aim is to manage the network in emergency conditions and to ensure in critical nodes an adequate pressure to deliver a higher flow rate. The procedures to identify the nodes where the pressure control should be implemented are based on calibration techniques and on sensitive matrices.

The analysis of the network has shown that the reduction of total circulating flow in the network is not relevant and it allows an improvement of the head in critical nodes.

Comparing the two procedures, the benefits obtainable in the critical areas of the network using the procedure based on sensitive matrices are more evident. 


\section{References}

Alvisi, S., \& Franchini, M. (2006). Pianificazione degli interventi di riabilitazione su di una rete acquedottistica mediante algoritmi genetici multi-obiettivo. XXX Convegno di Idraulica e Costruzioni Idrauliche. Roma.

Berardi, L., Colombo, A., \& Giustolisi, O. (2008). Analisi di affidabilità delle reti in pressione in presenza di valvole di intercettazione. XXXI Convegno Nazionale di Idraulica e Costruzioni Idrauliche. Perugia.

Bush, C., \& Uber, J. (1998). Sampling design methods for water distribution model calibration. Journal of Water Resources Planning and Management, 334-344.

Calomino, F., \& Veltri, P. (1980). Un procedimento di calcolo automatico per la verifica delle reti idrauliche in pressione a portate incognite in ingresso ed in uscita. XVII Convegno di Idraulica e Costruzioni Idrauliche. Palermo.

Caruso, O. (2017). Un modello di gestione delle reti idriche in condizioni di emergenza. PhD Thesis, University of Calabria,.

Farmani, R., Walters, G., \& Savic, D. (2005). rade-off between Total Cost and Reliability for Anytown Water Distribution Network. Journal of Water Resources Planning and Management, 161-171.

Gargano, R., \& Pianese, D. (200). Reliability as Tool for Hydraulic Network Planning. Journal of Hydraulic Engineering, 354 - 364.

Kapelan, Z., Savic, D., \& Walters, G. (2007). Calibration of Water Distribution Hydraulic Models Using a Bayesian Type Procedure. Journal of Hydraulic Engineering.

Kleiner, Y., Adams, B., \& Rogers, J. (1998). Selection and scheduling of rehabilitation alternatives for water distribution systems. Water Resource Research, 2053-2061.

Lansey, K., Duan, N., Mays, L., \& Tung, T. (1992). Optimal maintenance scheduling for water distribution systems. Civil Engineering Systems, 211-226.

Veltri, P., Fiorini Morosini, A., \& Orlando, F. (2010). a calibrazione delle scabrezze delle reti idriche: un approccio di tipo probabilistico basato su un modello PDA di risoluzione della rete. $L^{\prime}$ ACQUA, pp. 110-120.

Vrugt, J., Gupta, H., Bouten, W., \& Sorooshian, S. (2003). A Shuffled Complex Evolution Metropolis Algorithm for Optimization and Uncertainty Aassessment of Hydrological Model Parameters. Water Resources Research. 